\title{
An Empirical Study on the Identification of Driving Factors of Satisfaction with Online Learning Based on $\mathrm{TAM}^{*}$
}

\author{
Chunling Shao \\ Yiwu Industrial \& Commercial College \\ Yiwu, China 322000
}

\begin{abstract}
Taking technology acceptance model (TAM) as the research framework and by means of random sampling method and questionnaire method, the author has conducted an acceptance scale survey on 340 predictive questionnaires, and made a quadratic regression analysis on the questionnaire data with the aid of SPSS24.0 analysis software, so as to discuss the perceived satisfaction of online learning, as well as the influence of behavioral attitude, perceived usefulness, perceived ease of use, and behavioral intention on the perceived satisfaction. The results shows that perceived usefulness, perceived ease of use, attitude and behavioral intention have significant positive effects on perceived satisfaction of online learning. Behavioral intention of online learning performs a partially mediating function in perceived usefulness, ease of use, attitude and satisfaction. It can be seen that online learning attitude, perceived usefulness and ease of use can positively influence online learning satisfaction through behavioral intention, while there is no significant difference between male and female on the above variables.
\end{abstract}

Keywords-satisfaction; driving factors; TAM; online learning; empirical research

\section{INTRODUCTION}

With the development of network technology, online teaching, as a new form of teaching, is gradually widely used in all forms of education at all levels. National Outline for Medium- and Long-Term Educational Reform and Development (2010-2020) proposes to "strengthen the construction of online teaching resources system, introduce international high-quality digital teaching resources, and develop online learning courses". By means of online education platform, students can learn independently, download learning resources anytime and anywhere, interact with teachers, and cooperate and share among students, so as to realize knowledge construction. Online teaching has gradually become an inevitable trend in the development of education, and learners' perceived satisfaction is one of the core indicators to measure the formative assessment of

Chinese Library Classification Number: G434 Document Code: B

*Fund: the first batch of teaching reform research projects in the 13th Five-Year Plan of higher education in Zhejiang Province: "Exploration and Practice on the Path of Informatization Reform of Higher Vocational Accounting Education - A Case Study of Yiwu Industrial \& Commercial College" (jg20180719). online teaching. It is proved that perceived satisfaction can not only predict learners' learning effects and emotional tendency of continuous learning to a great extent, but also actively facilitate cooperation and sharing among learners, and effectively improve the effect of online learning [1] Therefore, it will be a practical task in the new era to study the model of identifying the driving factors of learners' perceived satisfaction with online teaching.

\section{LITERATURE REVIEW}

Relevant literature research shows that most online teaching platforms establish submodules based on administrator, teacher and student management, covering courses, tests, interactions, games and other functions [2], so as to strengthening students' independent learning. The study on online learning satisfaction started from the United States. At present, it has been proved that learners' behavioral intention and learning effects can be predicted to a certain extent through learners' satisfaction [3]. Japanese scholar Bray and others summarized the interaction between students and teachers, between students, between students and teaching content, and between students and platform interface, and the choice of students' independent learning as influencing factors of online learning satisfaction [4]. Lin Haiyan and $\mathrm{Yu}$ Jianning randomly divided students into the experimental class and the traditional class based on online learning. At the end of the semester, they conducted a questionnaire survey on students and compared their examination results. The results showed that students' final grade of the experimental class was higher than that of the traditional class, and their related satisfaction was significantly higher than the perceived satisfaction of students in the traditional class [5]. Taking Moodle teaching platform as an example, Chen Hongpu and Zhou Congcong proposed that online teachers played an indispensable leading role in the process of online teaching from the perspective of students [6]. Lim et al. hypothesized five influencing factors of satisfaction: technology and system, institutional factors, interactive application, student behavior and attitude, and teacher personality [7]. Based on the perspective of students' learning style and personality traits, Dai Zhuo and Zheng Xiaoting put forward that the reliability, content richness, system navigation, page aesthetics and 
driving factors of customer perceived satisfaction with online teaching platform with behavioral intention as a mediator factor by means of in-depth interview, literature research, questionnaire survey, data regression analysis and other methods to broaden the understanding of customer satisfaction theory from the perspective of educational services.

\section{RESEARCH DESIGN AND DATA COLLECTION}

have created relatively mature online learning evaluation scale by taking Technology Acceptance Model (TAM) as a theoretical model. In the empirical study based on TAM, Zhan Haibao and Zhang Liguo presented that technical support, perceived attitude and social influence had significant influences on online learning behavioral motivation [9]. Zhang Si, Wang Chunli, Zeng Yuhua, et al, on the basis of TPB and Tam models, took subjective norms, behavioral attitudes, and perceived behavioral control as consideration factors to build a model for teacher's online teaching behaviors (MTNTB) [10].

On the basis of TAM, this paper integrates information (IS), and attempts to construct a model of identifying the

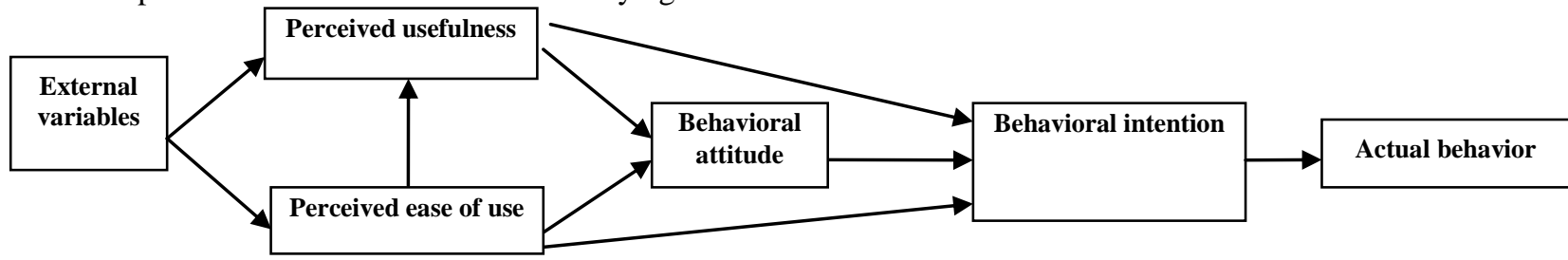

Fig. 1. Technology Acceptance Model (TAM).

TAM believes that system use is determined by behavioral intention, and behavioral intention is determined by behavioral attitude and perceived usefulness, and attitude is determined by perceived usefulness and ease of use, and perceived usefulness is determined by perceived ease of use and external variables, and perceived ease of use is decided by external variables. Furthermore, according to the theory of planned behavior decomposition of Todd and Taylor, attitudes can be decomposed into perceived usefulness, perceived ease of use and universality. Perceived usefulness and ease of use play a major role in the user's behavioral intention, and both perceived usefulness and perceived ease of use have positive influence on behavioral intention [12].

The research on sustainable use of information system (IS) is on the rise in recent years, which studies users' behavior and willingness to continue to use a specific information system after initial adoption. Bhattacherjee suggested an expectation confirmation model for the information system (IS) field. It was proved that expectation confirmation, perceived usefulness and satisfaction had a marked impact on users' willingness to continue to use, and perceived usefulness affected user satisfaction [13]. Hong S J, Tam K Y, Kim J and other scholars extended the ECM-IT model in subsequent research, introduced perceived interestingness and perceived ease of use into the usage perceived intention, and verified it in the study of mobile data service [14].

Starting from specific cases, Wang Naihan constructed a hierarchical model that included "learning platform, teaching interaction, and learning resources of network courseware" and other influencing factors of learner satisfaction. In line with the online platform course data records, Zeng Jialing, Lu Xinger et al constructed a structural equation model of satisfaction of distance learners based on learning motivation, learning process, learning ability and learning difficulty, and proposed that learning motivation could effectively improve satisfaction [15]. Through the above studies, the author found that the study on influencing factors of online learning satisfaction mainly focused on technology, teachers, resources and learners, and most of them emphasized that learners satisfaction presented positive correlation with learning behavioral intention. After discussion in the above literature, the research framework was set as shown in "Fig. 2 ", and relevant hypotheses were put forward, as shown in "Table I".

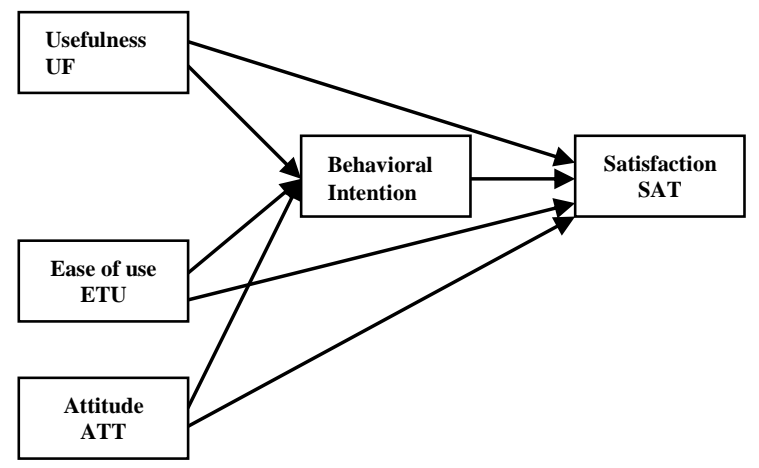

Fig. 2. Research framework. 
answering from high to low, which was used as the basis for the subscales of perceived usefulness, perceived ease of use, behavioral attitude, behavioral intention and satisfaction of online learning.

After that, according to the connotation of technology acceptance theory and Ajzen's suggestions and practices on questionnaire compilation, and with reference to the relevant items of the research on the influencing factors of flipped classroom learning satisfaction and its action mechanism (Zhai Xuesong, 2016), the questionnaire was modified into a model questionnaire of identifying driving factors of online learning satisfaction according to significant beliefs. The questionnaire mainly includes five parts: the first part is online learning behavioral attitude (ATT) scale, and the second part is the usefulness scale (UF), and the third part is ease of use (ETU) scale, and the fourth part is behavioral intention (BI) scale, and the fifth part is satisfaction (SAT) scale, with a total of 15 questions. The results were scored and assigned by the Likert 7-point scale, ranging from complete disagreement to complete agreement. The higher the item score, the higher the degree of agreement.

\section{Data Analysis}

The investigation team first sorted out and classified all the collected questionnaires, deleted invalid questionnaires, and coded the remaining valid questionnaires one by one. Secondly, SPSS24.0 statistical software was used for secondary regression analysis, aiming to explore the relationship between prior variables of online learning behavioral attitude and usefulness ease of use and intermediate variable behavioral intention, as well as the relationship between behavioral attitude, usefulness, ease for use, behavioral intention and learning satisfaction. Finally, the fitting degree of the model and the acceptance of hypothesis test are tested through path analysis.

\section{RESULTS AND ANALYSIS}

This empirical analysis mainly adopts the principal component analysis method. The indicator variables are subdivided into 5 factors, namely, online learning attitude, behavioral intention, usefulness, ease of use and satisfaction. The total explanatory ability is $75.22 \%$, and greater than $60 \%$ suggested by Hear. KMO value is 0.867 , and larger than the proposed value of 0.8 , so it is suitable for factor analysis. The approximate sig. value of Bartlett test of sphericity is less than 0.05 , so it is significant. The null hypothesis influence relationship is not rejected, indicating that there is correlation between the questions. As can be seen from "Table III", the prediction topics and total correlation values are all greater than 0.5 , and the Cronbach's Alpha of each factor is $0.848,0.781,0.757$, 0.865 and 0.849 respectively, which are all greater than 0.7 , showing that factors in this study have sufficient reliability and good internal consistency. 


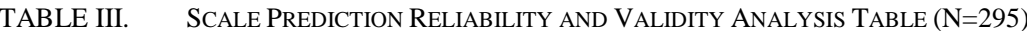

\begin{tabular}{|c|c|c|c|}
\hline Subscales & Items & $\begin{array}{c}\text { Topic and Total } \\
\text { Relevance }\end{array}$ & $\begin{array}{c}\text { Cronbach's } \\
\text { Alpha }\end{array}$ \\
\hline \multirow[t]{3}{*}{ Attitude } & Online teaching is a good idea (ATT1) & 0.785 & 0.848 \\
\hline & Online teaching should continue (ATT2) & 0.827 & \\
\hline & Online teaching will make me want to learn more (ATT3) & 0.558 & \\
\hline \multirow[t]{3}{*}{ Ease of use } & I think online learning is easy (ETU1) & 0.635 & 0.781 \\
\hline & I like online learning activities (ETU2) & 0.624 & \\
\hline & The operation of online learning must be very easy for me (ETU3) & 0.600 & \\
\hline \multirow[t]{3}{*}{ Usefulness } & Online teaching improves my learning performance (UF1) & 0.581 & 0.757 \\
\hline & Online teaching makes me like learning better (UF2) & 0.603 & \\
\hline & Online teaching can provide the appropriate course content (UF3) & 0.582 & \\
\hline \multirow[t]{3}{*}{ Behavioral intention } & I will actively participate in online learning courses (BI1) & 0.710 & 0.865 \\
\hline & I will hand in my homework on time (BI2) & 0.763 & \\
\hline & I will discuss with other students online (BI3) & 0.761 & \\
\hline \multirow[t]{3}{*}{ Satisfaction } & I can always find the right course online (SAT1) & 0.502 & 0.849 \\
\hline & $\begin{array}{l}\text { When I raise a problem and need to solve it, it is dealt with quickly } \\
\text { (SAT2) }\end{array}$ & 0.842 & \\
\hline & $\begin{array}{l}\text { I think the teaching resources of online teaching, such as PPT, video, } \\
\text { documents, etc., are complete (SAT3) }\end{array}$ & 0.846 & \\
\hline
\end{tabular}

The convergent validity AVE method is used for analysis, and the square root of convergent validity is taken to get discrimination validity, as shown in "Table IV". A total of 295 valid cases are collected in this survey, including 5 indicator variables, namely, behavioral attitude, perceived ease of use, perceived usefulness, behavioral intention and satisfaction, with the mean ranging from 4.685 to 5.205 and the standard deviation ranging from 0.826 to 1 . The convergent validity AVE of variables ranges from 0.538 to 0.666, in a good acceptable range (from 0.3 to 0.7 ).

TABLE IV. TABLE OF VARIABLE DESCRIPTIVE STATISTICS AND CONVERGENT VALIDITY ANALYSIS

\begin{tabular}{|l|l|l|l|l|l|}
\hline \multicolumn{1}{|c|}{ Variables } & $\begin{array}{c}\text { Convergent } \\
\text { validity AVE }\end{array}$ & $\begin{array}{c}\text { Discriminati } \\
\text { on validity }\end{array}$ & \multicolumn{1}{|c|}{ Mean } & \multicolumn{1}{c|}{$\begin{array}{c}\text { Standard } \\
\text { deviation }\end{array}$} & $\begin{array}{c}\text { Number of } \\
\text { cases }\end{array}$ \\
\hline Attitude (ATT) & 0.654 & 0.809 & 5.205 & 0.935 & 295 \\
\hline Satisfaction (SAT) & 0.619 & 0.787 & 4.685 & 0.969 & 295 \\
\hline Ease of use (ETU) & 0.538 & 0.734 & 5.113 & 0.839 & 295 \\
\hline Usefulness (UF) & 0.571 & 0.756 & 4.929 & 0.892 & 295 \\
\hline Behavioral intention (BI) & 0.666 & 0.816 & 4.888 & 0.826 & 295 \\
\hline
\end{tabular}

The analysis of correlation among variables is shown in "Table V". The triangle area at the lower left of the diagonal is the Pearson correlation coefficient of the factor, ranging from 0.414 to 0.588 . There is no too high or too low correlation (The acceptable correlation range is $0.3-0.7$ ). The discrimination validity of all variables is greater than the standardized correlation coefficient between the variable and other variables. That is to say, the validity of the prediction model is appropriate.

TABLE V. VARIABLE CORRELATION ANALYSIS TABLE

\begin{tabular}{|l|l|l|l|l|l|l|}
\hline \multicolumn{1}{|c|}{ Variables } & \multicolumn{1}{|c|}{$\begin{array}{c}\text { Convergent } \\
\text { Validity }\end{array}$} & ATT & SAT & ETU & UF & BI \\
\hline Attitude (ATT) & 0.809 & 1.000 & & & & \\
\hline Satisfaction (SAT) & 0.787 & 0.588 & 1.000 & & & \\
\hline Ease of use (ETU) & 0.734 & 0.414 & 0.510 & 1.000 & & \\
\hline Usefulness (UF) & 0.756 & 0.409 & 0.479 & 0.588 & 1.000 & \\
\hline Behavioral intention (BI) & 0.816 & 0.458 & 0.472 & 0.441 & 0.541 & 1.000 \\
\hline
\end{tabular}

The hypotheses of SPSS path analysis for prior variable and mediating variable behavioral intention, independent variables behavioral attitude, usefulness, ease of use and behavioral intention, and dependent variable satisfaction are verified as "Table VI". It can be seen from "Table VI": (1) The tolerance VIF of variables is less than 5, indicating that there is no collinearity between among variables. (2) DebinWatson is less than 2.5, showing that there is no autocorrelation among variables. (3) R2 ranges from 0.33 to 0.67 , showing that independent variables have a medium or above influence on the dependent variable. (4) The significance $\mathrm{p}$ value is less than 0.05 , demonstrating that there is a significant positive correlation between independent variables and hypothesised dependent variables, so the hypotheses $\mathrm{H} 1-\mathrm{H} 7$ are valid.

As can be seen from the Beta value in "Table VI", the influence of learning behavioral attitude has the greatest impact on learning satisfaction. For every increase of one standard deviation, satisfaction increases by 0.388 standard deviations. The influence of ease of use and behavioral 
intention on learning satisfaction decreases in turn, and satisfaction increases by 0.222 and 0.132 standard deviations for each increase of standard deviation. However, usefulness has the smallest impact on learning satisfaction, and satisfaction with only increases by 0.118 standard deviations for each increase of standard deviation.

Moreover, the Beta values of usefulness, learning attitude and ease of use on the mediating variable behavioral intention are $0.365,0.259$ and 0.119 respectively, showing that usefulness has the greatest influence on the mediating variable behavioral intention, followed by learning attitude, while ease of use has the smallest influence on the mediating variable behavioral intention. Prior variables further positively affect the dependent variable satisfaction by affecting the mediating variable online learning behavior intention.

TABLE VI. VERIFICATION OF RESEARCH HYPOTHESES

\begin{tabular}{|c|c|c|c|c|c|c|c|c|c|c|}
\hline \multirow{2}{*}{$\begin{array}{c}\text { Dependent } \\
\text { Variables }\end{array}$} & \multirow{2}{*}{$\begin{array}{c}\text { Independent } \\
\text { Variables }\end{array}$} & \multirow{2}{*}{$\begin{array}{c}\begin{array}{c}\text { Unstandardized } \\
\text { Coefficient }\end{array} \\
B \\
\end{array}$} & \multirow{2}{*}{$\begin{array}{l}\text { Standard } \\
\text { Error }\end{array}$} & \multirow{2}{*}{$\begin{array}{c}\begin{array}{r}\text { Standardizati } \\
\text { on Coefficient }\end{array} \\
\text { Beta } \\
\end{array}$} & \multirow{2}{*}{$\begin{array}{c}\text { T- } \\
\text { Value }\end{array}$} & \multirow{2}{*}{$\begin{array}{c}\text { Significance } \\
\text { P Value }\end{array}$} & \multicolumn{2}{|c|}{ Collinearity Statistics } & \multirow{2}{*}{$\begin{array}{l}\text { Durbin- } \\
\text { Watson }\end{array}$} & \multirow{2}{*}{$\mathbf{R 2}$} \\
\hline & & & & & & & Tolerance & $V I F$ & & \\
\hline \multirow[t]{5}{*}{ Satisfaction } & (Constant) & -0.109 & 0.315 & & -0.345 & 0.730 & & & 1.669 & 0.460 \\
\hline & Attitude & 0.402 & 0.052 & 0.388 & 7.658 & 0.000 & 0.726 & 1.377 & & \\
\hline & Usefulness & 0.128 & 0.063 & 0.118 & 2.029 & 0.043 & 0.549 & 1.821 & & \\
\hline & Ease of use & 0.256 & 0.064 & 0.222 & 4.019 & 0.000 & 0.609 & 1.641 & & \\
\hline & $\begin{array}{l}\text { Behavioral } \\
\text { intention }\end{array}$ & 0.155 & 0.064 & 0.132 & 2.440 & 0.015 & 0.631 & 1.584 & & \\
\hline \multirow{4}{*}{$\begin{array}{l}\text { Behavioral } \\
\text { intention }\end{array}$} & (Constant) & 1.431 & 0.278 & & 5.148 & 0.000 & & & 1.770 & 0.369 \\
\hline & Attitude & 0.229 & 0.046 & 0.259 & 4.936 & 0.000 & 0.787 & 1.271 & & \\
\hline & Usefulness & 0.338 & 0.055 & 0.365 & 6.171 & 0.000 & 0.621 & 1.610 & & \\
\hline & Ease of use & 0.118 & 0.058 & 0.119 & 2.015 & 0.045 & 0.618 & 1.618 & & \\
\hline
\end{tabular}

The independent sample $t$ test of gender was conducted for the five variables, and the verification results were shown in 'Table VII". The mean of male students' opinions on the ease of use (5.228) were higher than that of female students' (5.058), and the mean of their attitudes towards online learning (5.218) were also slightly higher than that of female students' (5.192), which was consistent with previous research results. An experimental study conducted by American AMES et al. at California State University shows that male students have a more positive emotional attitude toward computers than female students. Roy \& Chi from University of Pittsburgh conducted a study on students of Grade 8 in Pittsburgh's local secondary schools in terms of the use of computers for information search. The result indicates that female students prefer vertical search, while male students prefer horizontal search. Compared with the two search modes, the information obtained by the latter through the Internet is faster and more detailed than the former [16].

Generally speaking, for the five variables of learning attitude, satisfaction, perceived ease of use, perceived usefulness, and online learning behavioral intention, the mean difference and the significance $P$ value of t-test between male and female students are all greater than 0.05 , which demonstrates that male and female students have different views on the usefulness, ease of use, satisfaction, learning attitude and behavioral intention of online learning, but there is no significant difference.

TABLE VII. TABLE OF GENDER T-TEST

\begin{tabular}{|c|c|c|c|c|c|c|c|c|}
\hline & \multicolumn{3}{|c|}{ Mean Equivalence T Test } & \multirow{2}{*}{$\begin{array}{c}\text { Mean } \\
\text { difference }\end{array}$} & \multicolumn{4}{|c|}{ Descriptive Statistics } \\
\hline & t-value & $\begin{array}{l}\text { Degree of } \\
\text { freedom }\end{array}$ & Significance $p$ & & Gender & $\begin{array}{c}\text { Number of } \\
\text { cases }\end{array}$ & Mean & $\begin{array}{r}\text { Standard } \\
\text { deviation }\end{array}$ \\
\hline \multirow[t]{2}{*}{ ATT Attitude } & -0.218 & 293.000 & 0.827 & -0.026 & Female & 200 & 5.192 & 0.934 \\
\hline & -.214 & 175.733 & 0.831 & -0.026 & Male & 95 & 5.218 & 0.988 \\
\hline \multirow[t]{2}{*}{ SAT Satisfaction } & 0.593 & 293.000 & 0.554 & 0.072 & Female & 200 & 4.732 & 0.934 \\
\hline & 0.567 & 166.014 & 0.571 & 0.072 & Male & 95 & 4.660 & 1.056 \\
\hline \multirow[t]{2}{*}{ ETU Ease of use } & -1.627 & 293.000 & 0.105 & -0.170 & Female & 200 & 5.058 & 0.867 \\
\hline & -1.697 & 205.740 & 0.091 & -0.170 & Male & 95 & 5.228 & 0.771 \\
\hline \multirow[t]{2}{*}{ UF Usefulness } & 1.148 & 293.000 & 0.252 & 0.130 & Female & 200 & 4.968 & 0.861 \\
\hline & 1.090 & 162.659 & 0.278 & 0.130 & Male & 95 & 4.839 & 0.997 \\
\hline \multirow{2}{*}{$\begin{array}{l}\text { BI Behavioral } \\
\text { intention }\end{array}$} & 0.057 & 293.000 & 0.955 & 0.006 & Female & 200 & 4.880 & 0.890 \\
\hline & 0.056 & 182.797 & 0.955 & 0.006 & Male & 95 & 4.874 & 0.901 \\
\hline
\end{tabular}

\section{CONCLUSIONS AND SUGgestions}

\section{A. Conclusions}

This study mainly discusses the driving factors of online learning satisfaction, makes expansion on the basis of technology acceptance model, establishes the mode of identification of driving factors of online learning satisfaction, and empirically tests the seven hypotheses put forward by the model. The research results show that the seven hypotheses proposed in this paper have been effectively verified, and the positive influence of perceived 
ease of use, perceived usefulness and users' online learning behavioral attitude in TAM model on users' behavioral intention has also been verified. It is proved that the easier users perceive the use process of online education platform, the higher the usefulness of online education, the more serious the user's attitude towards online learning, the stronger the willingness to use the online platform, the higher the satisfaction of online learning. Among the factors directly affected above, online learning behavioral intention also has significant mediating effects on perceived ease of use, perceived usefulness and behavioral attitude. In other words, perceived usefulness, perceived ease of use, online learning behavioral attitude and so on also positively affect users' behavioral intention and then indirectly affect users' satisfaction. However, there is no significant difference between men's and women's views on these factors.

In the specific empirical study, it is noteworthy that "perceived ease of use" and "perceived usefulness" can significantly affect students' online learning satisfaction, and the influence degree of "perceived ease of use" is higher than that of "perceived usefulness". This is contrary to previous studies by Karahanna, Davis and Lin Jiajing [17]. Considering all relevant factors, there may be three problems as follows. First, the design of questionnaire items for online learning perceived usefulness is not reasonable enough to accurately reflect the students' correct perception of online learning usefulness. Second, China's online learning has not yet popularized, and many people have not actually experienced online learning. Third, the construction of China's online learning website is still at the exploration stage, and website design and function development, website resource construction are not enough. As a result, students' perception of the usefulness of online learning is not high, so they pay more attention to the ease of use of online learning.

\section{B. Suggestions}

Online learning perceived usefulness, ease of use, attitude and learning behavioral intention have remarkable positive influence on perceived satisfaction, while perceived usefulness, ease of use and learning attitude significantly positively affect perceived satisfaction through behavioral intention. Therefore, in the construction of online learning platform, it is necessary to improve the perceived usefulness and ease of use of online learning, strengthen the positive attitude of online learning, and enhance the behavioral intention of online learning, so as to improve the online learning satisfaction. To achieve the above goals, the core task is to upgrade the quality management of the network teaching platform. When constructing the online learning platform, all institutions should lay emphasis on users' online experience, and fully consider whether the online teaching platform is equipped with abundant information resources, friendly interface, timely feedback, diverse teaching forms, good links and other multidimensional factors, so as to strengthen learners' perceived usefulness and ease of use.

At the same time, it can refer to the design thought of online games, create different task circumstances and carry out role-playing by means of virtual network. The learner can earn some scores by completing each learning task, keeping certain learning time and obtaining different learning evaluation performance and so on, and the score corresponds to the virtual identity and authority at different levels. Based on this links, we can regularly launch identitylevel bonuses and rewards activities, improve user promotion mechanisms to stimulate and enhance students' active learning attitudes and behavioral intentions, attract more teachers, students and the public to join the online learning camp, and promote the country to vigorously develop the reform policy of online education.

\section{Future Research Direction}

This paper studies the driving factors of online learning satisfaction, obtains four dimensions of online learning satisfaction including perceived usefulness, ease of use, behavioral attitude, behavioral intention by means of random in-depth interview and questionnaire survey, and builds a model of the identification of satisfaction driving factor by taking online learning behavioral intention as a mediating variable, to break through the previous TAM-based behavioral intention research, as well as a research of directly using resources, teachers, interaction and other online platform construction indicators as satisfaction measurement.

This study highlights the satisfaction of the perceptive subject, reflects the subjectivity and initiative of the object of education, and the two dimensions of behavioral attitude and behavioral intentions highlight the students' pursuit on the education individual value and their strong self-awareness and self-motivation. The subsequent research suggests that students, teachers, and other role categories should be added on the basis of the existing four dimensions to explore the driving factors of online learning perception satisfaction.

\section{REFERENCES}

[1] Dai Xinlai, Guo Ka, Liu Lei. An Empirical Study on the Influencing Factors of MOOC Learners' Satisfaction [J]. Modern Distance Education, 2017 (2): 17-23. (in Chinese)

[2] Wang Yuyang. Design and Implementation of Multi-element Network Teaching Platform based on Information Technology [J]. Modern Electronics Technique, 2017, 40 (19): 37-40. (in Chinese)

[3] Tsai, C.-C., Lin, S. S.,-Tsai, M-J. Developing an Internet Attitude scale for high school students $[\mathrm{J}]$. Computers \& Education, 2001 (01): 41-51.

[4] Sun Qiwu. Reviewing the Studies on Teacher's Interaction Behavior [J]. Shanghai Research on Education, 2002 (09): 39-42. (in Chinese)

[5] Lin Haiyan, Yu Jianing. Exploration on the Reformation of the Examination Mode of Traditional Chinese Pharmacology based on Network Teaching Platform [J]. Chinese Medicine Modern Distance Education of China, 2016 (03): 25-26. (in Chinese)

[6] Chen Hongpu, Zhou Congcong. On the Leading Behavior and Strategy of Online Teachers in the Network Environment [J]. Fujian Computer, 2013 (08): 28-31. (in Chinese)

[7] Zeng Jialing, Lu Xinger, Yang Yang, Wu Xiuhan, Zheng Qinhua. Research on the Influencing Factors of Distance Learners' Satisfaction Based on Structural Equation [J]. Distance Education in China, 2016 (08): 59-65+80. (in Chinese)

[8] Dai Zhuo, Zheng Xiaoting. Research on the Influencing Factors of Satisfaction with Network Teaching Platform [J]. Distance Education in China, 2014 (04): 50-56. (in Chinese) 
[9] Zhan Haibao, Zhang Liguo. Understanding of College Students to Adopt the Network Teaching Platform --An Empirical Study Based on TAM [J]. Modern Distance Education, 2015 (03): 53-59. (in Chinese)

[10] Zhang Si, Wang Chunli, Zeng Yuhua. Construction of Teachers' Online Teaching Behavior Model Based on TPB and TAM [J]. Distance Education in China, 2014 (01): 64-69. (in Chinese)

[11] Ajzen. From intention to action: A theory of planned behavior, In J.Kuhl \&J.Beckman (Eds.). Action control: From cognition to behavior [J].NY:springer-Verlag.1991 (04) : 11-39.

[12] Duan Wenting, Jiang Guangrong. A Review of the Theory of Planned Behavior [J]. Advances in Psychological Science, 2008 (02): 315-320.

[13] Bhattacherjee, A. An empirical analysis of the antecedents of electronic commerce service continuance [J]. Decision Support Systems, 2001, 32(02) : 201.

[14] Hong S J, Tam K Y, Kim J. Mobile data service fuels desire for uniqueness [J]. Communication of the ACM, 2006 (09): 89.

[15] Zeng Jiangling, Lu Xinger, Yang Yang, et al. Research on the Influencing Factors of Distance Learners' Satisfaction Based on Structural Equation [J]. Distance Education in China, 2016 (8): 59-65. (in Chinese)

[16] Guo Lingling. A Review of Gender Differences in Online Learning [J]. Journal Of Shandong TV University, 2008 (04): 16-20. (in Chinese)

[17] Lin Jiajing. Research on the Key Influencing Factors of Digital Learning Satisfaction [D]. Kaohsiung: National Kaohsiung Normal University, 2003. (in Chinese) 